\title{
Unilateral albinism with bilateral retinitis pigmentosa- a diagnostic challenge
}

\begin{abstract}
We report a rare case of unilateral ocular albinism in a female with bilateral retinitis pigmentosa. The patient had heterochromia irides with albinoid fundus in the same eye. The unique features in our case are association with retinitis pigmentosa, females rarely affected, uniocular presentation of albinism which has never been reported earlier, minimal refractive error, no nystagmus/strabismus, well maintained stereopsis, negative family history. There was history of consanguineous marriage present in the patient, her parents and also her grandparents. A thorough physical \& systemic examination should be done in such a patient to rule out life threatening disorders. Pedigree charting, discouraging consanguineous marriages, genetic counseling and if needed genetic testing should always be done.
\end{abstract}

Keywords: albinism, retinitis pigmentosa, bony spicules, heterochromia irides
Volume 2 Issue 5 - 2015

Rhibhu Soni,' Rubina T Soni, ${ }^{2}$ Preetam Singh, ${ }^{3}$ Vipin KVig, ${ }^{3}$ Rajbir Singh ${ }^{3}$

'Consultant Vitreo-retina services, SGHS Advanced eye care center, Ludhiana

${ }^{2}$ Consultant Ophthalmologist, GTB Hospital, Ludhiana ${ }^{3}$ Consultant Vitreoretina services, SB. Dr. Sohan Singh Eye Hospital, India

Correspondence: Rhibhu Soni, SGHS Advanced eye care center, Top Enclave, Pakhowal Road, Ludhiana, Punjab, India, Tel +9|8872 I I I I50,Email soni_rhibhu@yahoo.com

Received: June 24, 2015 | Published: July 07, 2015
Abbreviations: AR, autosomal recessive; RE, right eye; LE, left eye; BE, both eyes; RP, retinitis pigmentosa; VEP, visual evoked response; ERG, electroretinogram

\section{Introduction}

Albinism is a group of genetic conditions that causes a lack of pigment. It is of two types:

\section{i. Ocular albinism}

ii. Oculocutaneous albinism.

Ocular albinism can be X-linked and Autosomal Recessive (AR). In $\mathrm{X}$ linked form males are affected. There is marked deficiency of pigment in iris \& choroid associated with nystagmus, myopic astigmatism, foveal hypoplasia \& tessellated fundus. Female carriers have partial iris transillumination and fundus pigment mosaicism with chocolate spots in periphery. In AR form females are as severely affected as males. Lack of tyrosinase enzyme in the biochemical pathway prevents the formation of melanin in a patient of albinism. We here report a unique case of unilateral Ocular Albinism in a female which is also associated with retinitis pigmentosa. To the best of our knowledge no such case has been reported in the literature so far.

\section{Case report}

A 34 years old female presented to us with complaints of headache and bilateral eye ache since past 2 months she gave a history of nyctalopia since 6 years. On examination she was noticed to have heterochromia iridis which she on asking told was present since birth. She did not give any history of unilateral anhydrosis. There was no history of using any topical/systemic medications or any other glaucoma medications. She had no past history of any ocular trauma or ocular surgery. She told that she had grey forelock for which she was using a hair color since past 7-8 years. History of consanguinity was present in the patient as well as in her parents \& grandparents. On General Physical Examination she was moderately built and nourished. Her skin color and hair color were normal (using hair color).

Her unaided vision was 20/60 in Right Eye (RE) \& 20/80 in Left Eye (LE), which improved with refractive correction to 20/20 Both Eyes (BE). Color vision was normal in BE. Intraocular Pressure in $\mathrm{BE}$ was $16 \mathrm{~mm} \mathrm{Hg}$ by Goldmann applanation tonometer. Anterior segment examination revealed blue iris in RE and brown in LE (Figure 1). Pupil size and reaction were normal BE. Fundus of RE was albinoid with unmasking of the choriocapillaris with bony spicules present in the equatorial region, arteriolar attenuation \& waxy pallor of disc (Figure 2). LE showed no albinoid changes but bony spicules, arteriolar attenuation \& waxy pallor of disc was present (Figure 3). Her OCT (macular thickness and RNFL thickness) done was normal BE (Figure 4\&5). Her VEP done was abnormally low suggestive of optic pathway defect (Axonal type) (Figure 6\&7). Her pedigree is shown in (Figure 8). She was prescribed photo chromatic spectacles and was kept under follow-up. Examination of the patient's $1^{\text {st }}$ degree relatives showed no such features.

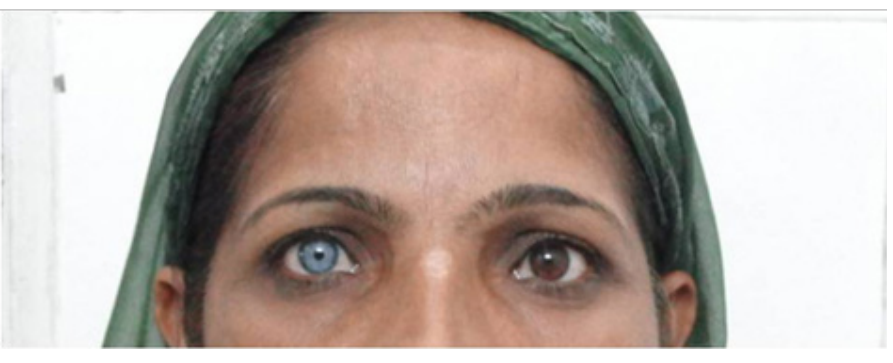

Figure I Heterochromia irides - right eye has blue iris and left brown. 


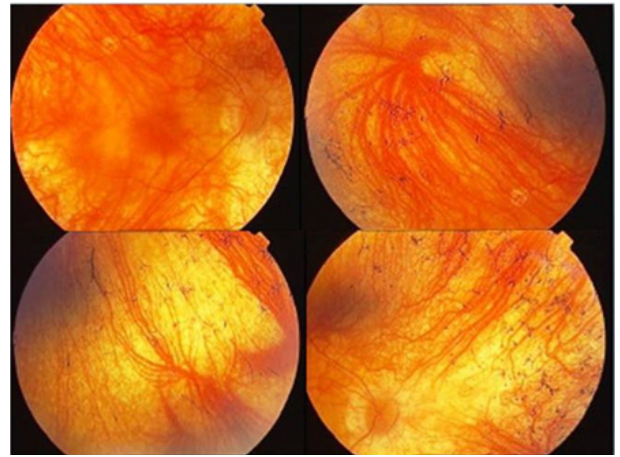

Figure 2 Right eye shows albinoid findus with unmasking of choroidal vessels and bony spicules in periphery.

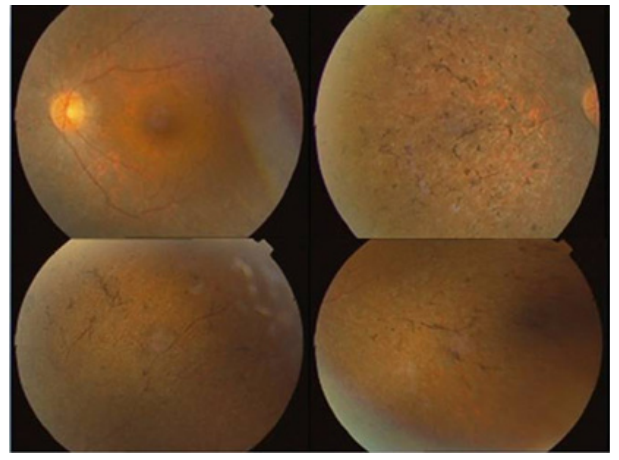

Figure 3 Left eye shows just arteriolar attenuation with bony spicules with no unmasking of choroidal vessels.
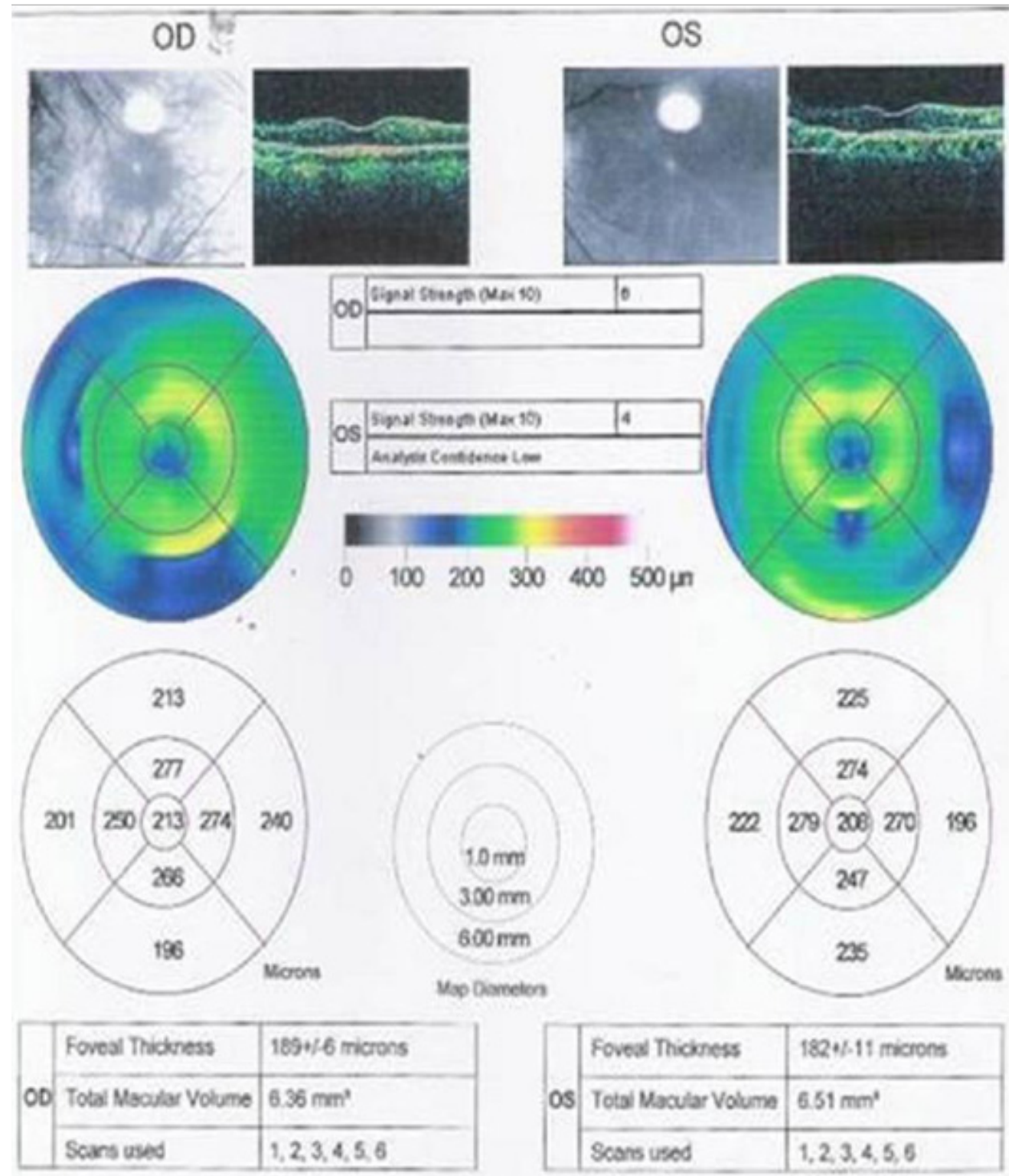

\begin{tabular}{|c|c|c|}
\hline \multirow{3}{*}{ OD } & Foveal Thideness & $189+/ 6$ microns \\
\hline & Total Mocular Volume & $6.36 \mathrm{~mm}$ \\
\hline & Scans used & $1,2,3,4,5,6$ \\
\hline
\end{tabular}

\begin{tabular}{|l|l|l|}
\hline & Foved Thichess & $182,4 \cdot 11$ microns \\
\hline OS & Total Macular Volume & $6.51 \mathrm{~mm}^{\prime}$ \\
\hline Scans used & $1,2,3,4,5,6$ \\
\hline
\end{tabular}

Figure 4 Macular thickness map showing normal macular thickness. 


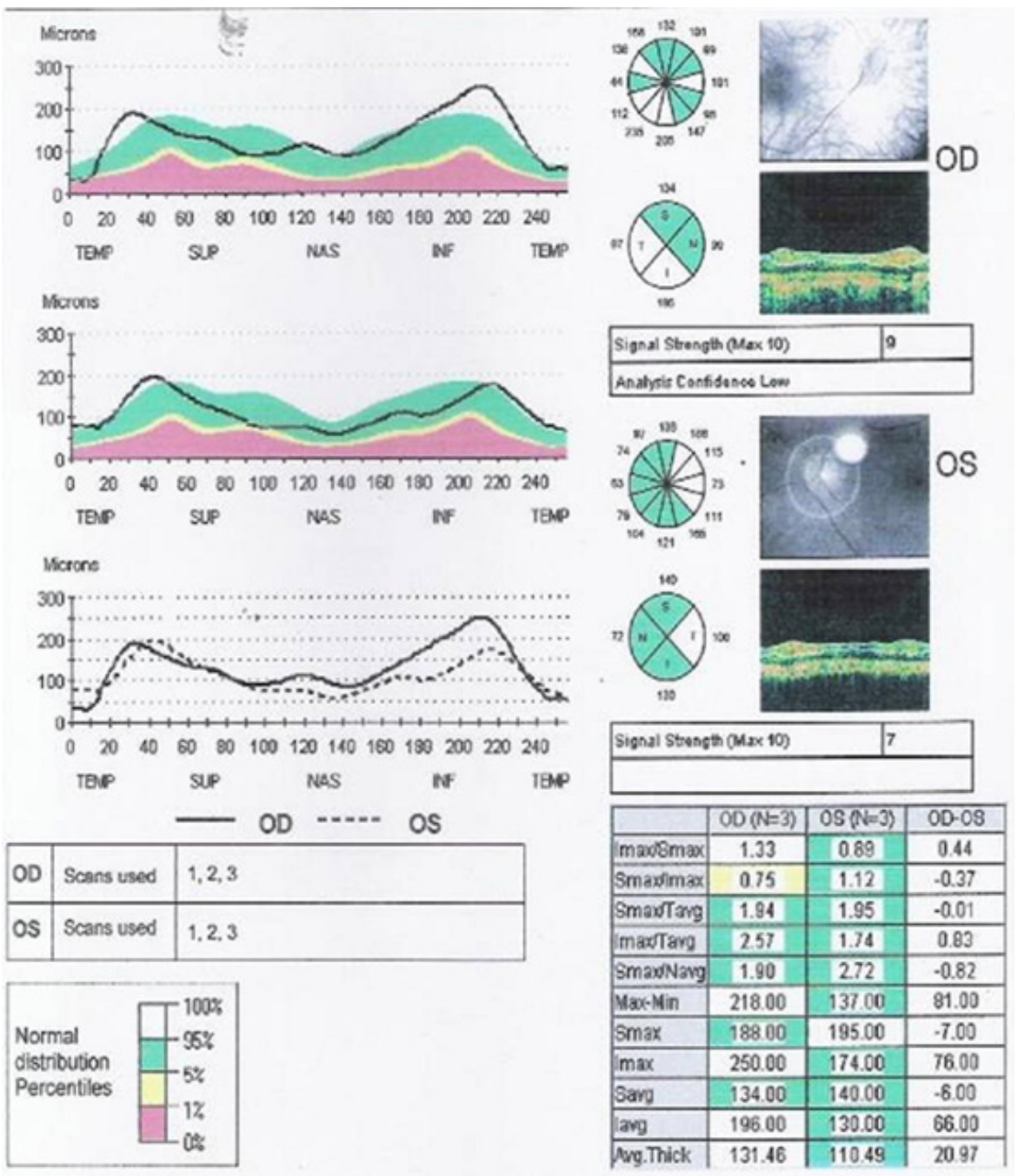

Figure 5 RNFL thickness map showing normal RNFL thickness.

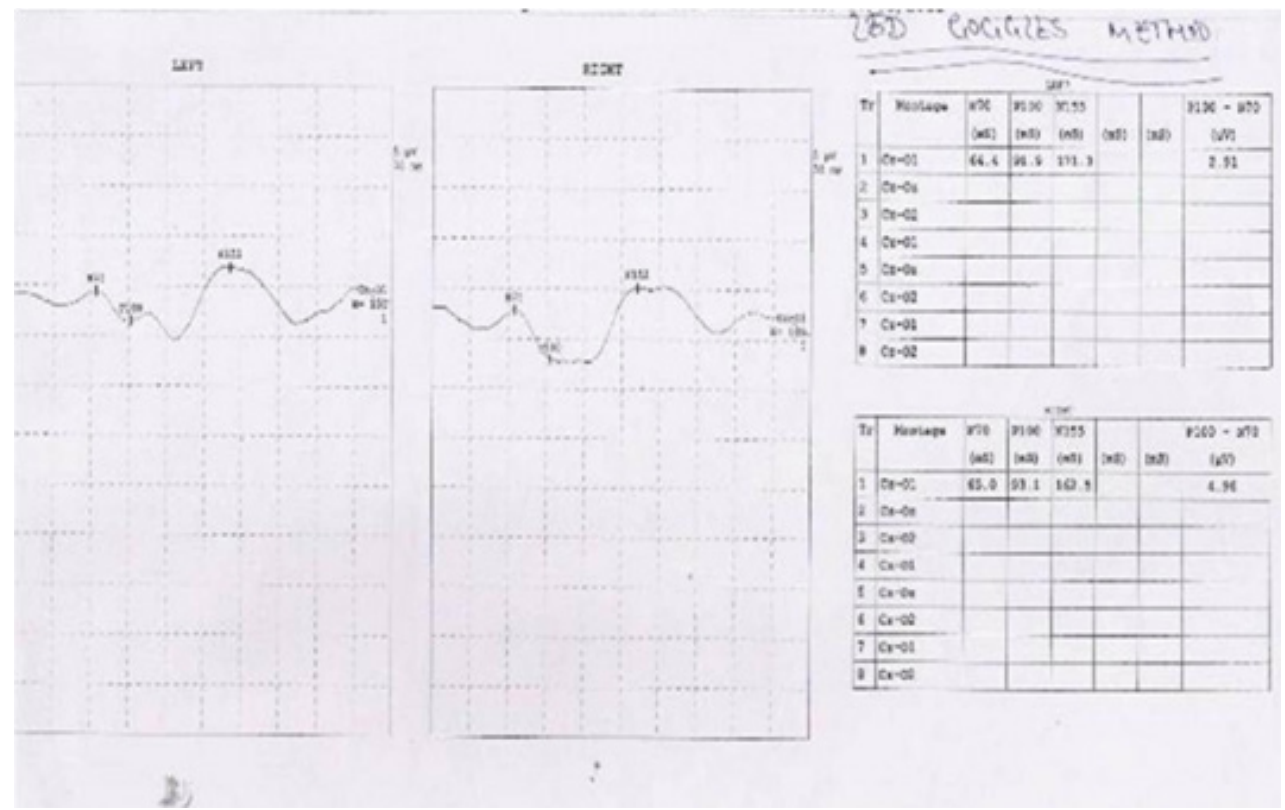

Figure 6 VEP report showing optic pathway dysfunction.

Citation: Soni R, Soni RT, Singh P, et al. Unilateral albinism with bilateral retinitis pigmentosa- a diagnostic challenge. Adv OphthalmolVis Syst. 20I5;2(5):I55-I59. DOI: I0.15406/aovs.2015.02.00059 


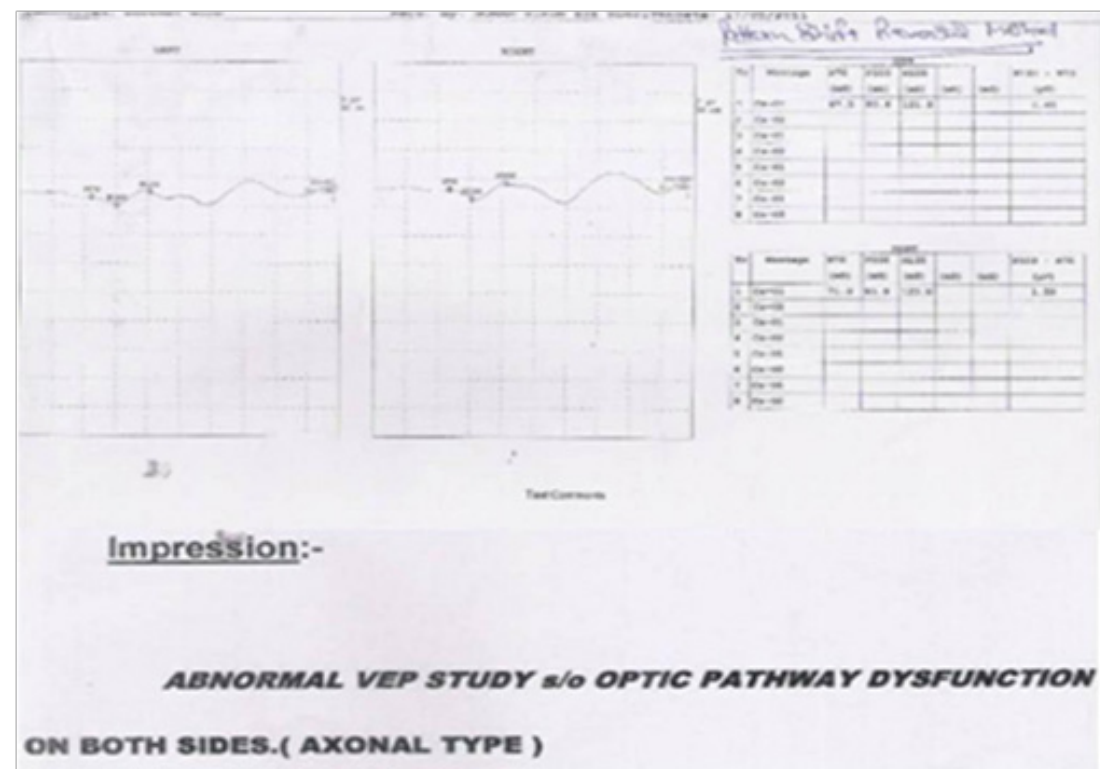

Figure 7 VEP report showing optic pathway dysfunction.

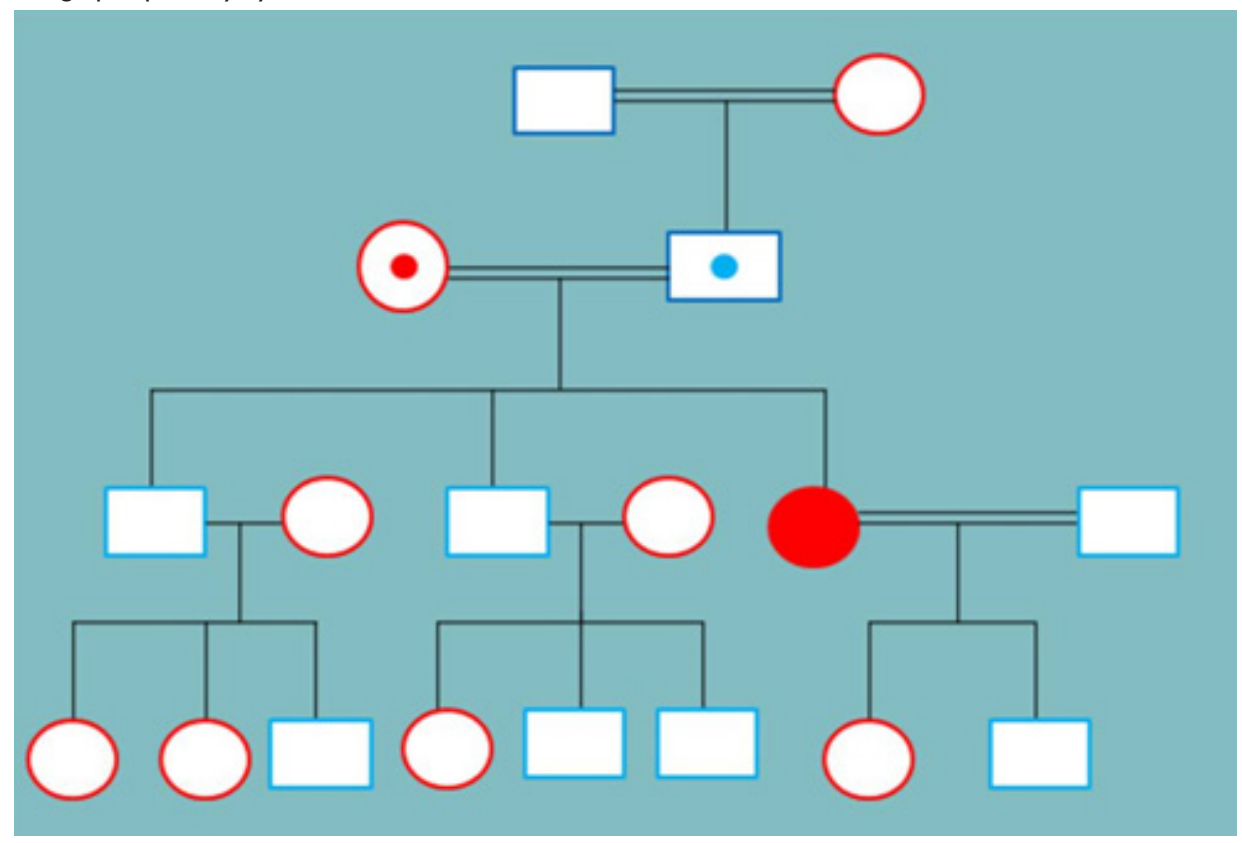

Figure 8 Pedigree chart of the patient showing normal family members with consanguinity among the patient, patient's parents and grandparents.

\section{Discussion}

On seeing the overall features and history we made the provisional diagnosis of Retinitis pigmentosa which can be associated with any one of the following:

1. Unilateral albinism

2. Congenital Horner syndrome

3. Fuch's uveitis

4. Familial herterochromia

5. Waardenburg syndrome
6. Glaucoma medications

7. Glaucoma

8. Neurofibromatosis

9. Eye injury (Siderosis bulbi)

The final diagnosis of exclusion was unilateral albinism with bilateral retinitis pigmentosa (RP). Waardenburg syndrome was thought of because of white forelock, heterochromia irides and albinoid fundus but the major criteria which are required to confirm the diagnosis of the same like, hearing loss, lateral displacement of inner canthus, confluent eyebrows, bilaterality of albinoid fundus $\&$ first degree relative affected by same were not met so it was also 
excluded. To establish the diagnosis of albinism, the presence of nystagmus, reduced iris and retinal pigment, foveal hypoplasia, and reduced visual acuity, taken in concert with hypo pigmentation of the skin and hair, are usually sufficient to confirm the clinical diagnosis. Stereopsis is also reduced because more than $70 \%$ of the fibers cross the optic chiasm.

If any of the above signs is absent in a person with albinism, selective Visual Evoked Response (VEP) testing may demonstrate aberrant optical pathways. ${ }^{2}$ Electroretinogram (ERG) is not specific and not required. GPR143 (formerly known as OA1) is the only gene in which mutations are known to cause X-linked ocular albinism. ${ }^{3,4}$ The unique features in our case are association with RP, females rarely affected, uniocular presentation of albinism which has never been reported earlier, minimal refractive error, no nystagmus / strabismus, well maintained Stereopsis and negative family history. Other ocular findings which can be present in a patient with albinism are extraocular muscle palsy, corneal opacity, partial aniridia, persistent pupillary membrane, capsular cataract, optic atrophy, retinal aplasia \& duplication of some portion of posterior retina. ${ }^{5}$ So a thorough ocular examination is warranted.

Some forms of albinism are associated with decreased platelet counts, increased susceptibility to infections, mental retardation \& skin neoplasm. So a thorough systemic examination in consultation with physician \& a dermatologist should be done. To confirm the diagnosis of such a case we should look into the clinical features, VEP testing \& hair bulb test for tyrosinase activity with $1 \%$ L-Dopa can be done. We confirmed the diagnosis on the basis of clinical features and VEP though Tyrosinase activity testing was not done. For any such case reporting in the OPD Pedigree charting should be done \& consanguineous marriages should be discouraged. Genetic counseling, examination of the patients $1^{\text {st }}$ degree relatives and if needed genetic testing should also be promoted.

\section{Funding}

None.

\section{Acknowledgments}

None.

\section{Conflicts of interest}

The authors have no conflicts of interest to declare.

\section{References}

1. King RA, Jackson IJ, Oetting WS. Human albinism \& mouse models. Molecular genetics of inherited eye disorders. Switzerland: Harwood Academy; 1994. p. 89-122.

2. Creel D, Witkop CJ, King RA. Asymmetric visually evoked potential in human albinos: Evidence for visual system anomalies. Invest Ophthalmol. 1974;13:430-440.

3. Oetting WS, King RA. Molecular basis of albinism, mutations \& morphogenesis of pigmentation genes associated with albinism. Hum Mutat. 1999;13(2):99-115.

4. Kerr R, Stevens G, Manga P, et al. Indentification of P gene mutation in individuals with oculocutaneous albinism in Sub- Saharan Africa. Hum Mutat. 2000;15(2):166-172.

5. Oetting WS, Summers CG, King RA. Albinism and the associated ocular defects. Metab Pediatr Syst Ophthalmol. 1994;17(1-4):5-9. 